totalled $\$ 4$ I 20 . Another, with seven slaves worth \$1900, came to $\$ 2897$. Estates with one or two slaves were of trivial amounts apart from the slaves.

Those who are interested in the subject will find here excellent material for comparison with the findings of some such standard book on the subject as Phillips's American Negro Slavery.

\title{
The Williams Fuel Collection
}

THE above title is used to designate temporarily the numerous runs of chemical engineering journals for the period I $890-1920$ which have just come in by purchase from the library of $\mathrm{H}$. J. Williams. Mr. Williams was for many years the chemical expert in the fuel division of the Boston Elevated Railway Company. This mass of material will be especially interesting to students concerned in those aspects of industry in which fuel consumption plays a prominent part, as its original purpose was to give information which would be useful in the purchase of the most satisfactory and economical type of fuel for the operation of the Elevated - coal, oil, or whatever it might be.

There are many reports from the Geological Surveys, both state and federal, also sets of such publications as the Proceedings of the American Chemical Society and the Journal of the Society of Chemical Industry (London). It is a convenient concentration of material just a bit out of the ordinary path of business history.

\section{New England's Cotton Mills}

How the Records for their Story Were Discovered To write the history of an industry in the days before income-tax returns and statistical departments is a baffling task. In the absence of complete records of any sort, - for the industry, for a locality, or even for a single company, - every scrap of evidence becomes a pearl of great price. Every production sheet or worker's contract, every order for machinery or letter about the business, must be used to fill in the blank spaces of the picture. The writer, in trying to piece together in this way the history of the first sixty years of the New England cotton industry, I790-1 $85^{\circ}$, was led into an absorbing treasure hunt which took her throughout the length 